\title{
Really Expressive Presuppositions and How to Block Them
}

\author{
Teresa Marques and Manuel García-Carpintero \\ LOGOS, Department of Philosophy, \\ BIAP - Barcelona Institute of Analytic Philosophy \\ University of Barcelona
}

\begin{abstract}
Kaplan (1999) argued that a different dimension of expressive meaning ("use-conditional", as opposed to truth-conditional) is requiredto characterize the meaning of pejoratives, including slurs and racial epithets. Elaborating on this, writers have argued that the expressive meaning of pejoratives and slurs is either a conventional implicature (Potts 2007) or a presupposition (Macià 2002 and 2014, Schlenker 2007, Cepollaro and Stojanovic 2016). We argue that an expressive presuppositional theory accounts well for the data, but that expressive presuppositions are not just propositions to be added to a common ground. We hold that expressives, including pejoratives and slurs, make requirements on acontextualrecord governed bysui generisnorms specific to affective attitudes and their expressions.
\end{abstract}

Keywords: pejoratives, slurs, expressive meaning, presuppositions

\section{Introduction}

Kaplan (1999) started a fruitful debate on the meaning of pejoratives, including slurs and racial epithets, as in 'there are too many charnegos in our neighbourhood'. ${ }^{1}$ Kaplan adds a "use-conditional" expressive dimension to the truth-conditional element. ${ }^{2}$ Hom $(2008,2012)$ defends instead a truth-conditional account. On his view, a slur like 'charnego' makes a truthconditional contribution - a property with a necessarily empty extension, which can be roughly expressed as: ought to be treated with contempt, and ought to be subject to exclusion from advancement to managerial positions, and..., because ofspeaking Spanish, being lazy, uncultured, and... all because descending from Spanish people outside Catalonia, (Hom 2008, 431). A main difficulty for Hom's view is the projection behaviour of slurs and pejoratives

\footnotetext{
1 'Charnego' or 'xarnego' is a slur coined in Catalonia for Spaniards from other Spanish regions that migrated to Catalonia (mostly during the 1950s and 60s) and their descendants. It appears to have its origin in 'lucharniego', a word that describes a mixed breed dog or a mongrel. Cf. Marques (2019) for data on how racist attitudes towards Spanish people without a well-established Catalan pedigree have persisted in Catalonia until today. It is an unfortunate requirement of our project to quote expressions that may cause offense, even in such uses. We mean to avoid uses that might trigger morally warranted offense, or even rationally felt offense (Bolinger2017).

${ }^{2}$ See Guttmann (2015) for elaboration.
} 
(Jeshion 2013a, 316-9; Sennet \& Copp 2015, 1102; Camp 2018, 35). When sentences with pejoratives are negated, antecedents of conditionals, embedded under modal operators, or in interrogative or directive mood, they still derogate the relevant target. ${ }^{3}$ To account for that behaviour, several writers have argued that the expressive meaning of pejoratives and slurs is either a conventional implicature (Potts 2007, Vallée 2014) or a presupposition (Macià 2002 and 2014, Schlenker 2007, Cepollaro and Stojanovic 2016). ${ }^{4}$ In defence of a truth-conditional account, Hom (2012, 398-401) and Hom \& May (2013, 298-300) appeal instead to conversational implicatures. Bolinger (2017) and Nunberg (2018) provide alternative pragmatic accounts.

We agree with presuppositional accounts. We think, however, that it is essential to understand expressive meanings along normative lines. Speech acts make different illocutionary contributions to contexts. ${ }^{5}$ On the view presented below, pejoratives in general and slurs in particular trigger normative, non-propositional presuppositions that require speakers and hearers to share some specific reactive attitude. ${ }^{6}$ We argue that this explains why the affective dimension of a pejorative normally projects, why the offensiveness of a slur does not depend on the truth or falsity of a presupposed or implicated content, and how a use of a slur insults. It also explains the difficulty in articulating the derogatory content that is communicated, for it does not just consist in descriptive information. ${ }^{7}$

\section{QUD, Conventional Meaning, Evaluative Attitudes}

\subsection{The Complexity of Contexts}

Contemporary semantics assumes two influential notions of context: Kaplan's (1989), on which contexts are sets of predetermined parameters, and Stalnaker's (1978), on which

\footnotetext{
${ }^{3}$ We have argued that the truth-conditional meaning that Hom $(2008,2012)$ proposes, including a deontic modal ought to..., does not determine an empty extension (Marques ms). Cf. also Sennet \& Copp (2015) and Cepollaro $\&$ Thommen (2019). Diaz-Leon (2019) offers a novel defense of the truth-conditional account that we can't discuss here.

${ }^{4}$ Williamson (2009) characterizes expressive contents as conventional implicatures, but he understands that category in a traditional way, wider than the one we assume following Potts's work (ibid., 151, 153). We take his view to be compatible with our presuppositional account as much as with Potts's. We find it difficult to classify Lycan's (2015) and Bach's (2018) views, cp. Bach 2018, 65, 72.

${ }^{5}$ García-Carpintero (2018) defends a normative account of presuppositions themselves as ancillary speech acts, developing a suggestion previously made by Sbisà $(1999, \S 4)$. Our proposal here doesn't depend on it. We'll submit that it is what is presupposed itself in the case of pejoratives and slurs that has a normative, nonpropositional character.

${ }^{6}$ Cf. Diaz-Legaspe (2019) on how to identify slurs. We endorse her second "broad definition", on which slurs are group pejoratives intended to apply to members of a neutrally identifiable group.

${ }^{7}$ Cf. Bolinger $(2017,439)$ for a good summary of the features of slurs that good accounts should explain, with further references to the literature highlighting them; see also her contribution to this volume, $\S 1.1$.
} 
contexts are sets of propositions that are "common ground". Granting Lewis (1980)'s point that Kaplanian contexts already include common ground contexts, we'll stick to a Stalnakerian view. ${ }^{8}$ Now, Stalnaker $(1978,2014)$ defines contexts as a set of propositions, but recent work shows that this is not accurate. Questions make contributions to context, but they differ from those that declaratives make. Elaborating on previous work by Carlson (1982) and others, Roberts $(2012,2018)$ suggests that contexts are structured by a question under discussion (QUD), for which discussants try to provide adequate answers.

Contexts must thus be illocutionarily structured. ${ }^{9}$ They include the Stalnakerian set of propositions to which speakers are assertorically committed, formally modelled as the context set - the set of possible worlds compatible with the presumed common knowledge of the participants, "a body of information that is available, or presumed to be available, as a resource for communication" (Stalnaker 2014, 24). Accepted assertions add the propositions to which speakers are committed under a doxastic mode to the context set. But speakers are also committed to the questions that direct their inquiry, updated by new questions and by the assertions that partially answer them. If we ask, "where should we go for dinner?", we are committed to our audience getting a reason for answering; the answer "let's go to an Italian place" presupposes the question, and further constraints the class of possible answers. In felicitous cases, both components - the assertoric commitments and those comprising the QUD - are mutually known, as different classes of mutually shared commitments.

Questions can be taken as a particular kind of directive (what utterances of imperative sentences signify by default). Directives also help to establish the illocutionary structure of contexts. Semantic accounts have been advanced on which they also differ from assertions, contributing to contexts specific objects, plans. ${ }^{10}$ Contexts thus include at least a Stalnakerian common ground (the propositions that are accepted as true), QUD, and a set of plans. We suggest that they also include the contents of other evaluative states, subject to distinctive norms: emotions and "reactive attitudes" (Strawson 1968). ${ }^{11}$ While assertives add propositions that are taken for granted to the common ground, directives and interrogatives

\footnotetext{
${ }^{8}$ We'll assume Lewis' (1979) scorekeeping model of context as a variant of the view.

${ }^{9}$ García-Carpintero (2015, forthcoming) offers further considerations for the view, and Gutzmann (2015) a nice formal implementation. On our view, however, the components of contexts - the scoreboard - are not just representational states or their contents. They are rather contents that are subject to norms to which speakers are liable.

${ }^{10}$ Gibbard (1990, ch. 5) offers a classical proposal. Charlow (2018), Portner (2016), and Roberts (2018) provide alternatives.

${ }^{11}$ Reactive attitudes are moral attitudes we have towards other agents qua persons, for instance gratitude, resentment, disgust or anger.
} 
add plans and QUDs, expressives like slurs add contents that are taken to make fitting emotional and reactive attitudes shared by interlocutors. ${ }^{12}$

To sum up, contexts are illocutionarily structured and are constituted by different classes of contents to which speakers are committed in different modes: in the way we are committed to beliefs, but also in the way they are committed to intentions, to affective attitudes, and to the questions guiding their inquiries. In felicitous cases, these different commitments are mutually shared, and license presuppositions (García-Carpintero 2015, forthcoming; Green 2017, 1591-3; Thomason 1990, 338). On Stalnaker's (1978) account, an accepted assertion comes to be presupposed afterwards, allowing for the satisfaction of presuppositional requirements later on in the discourse. Similarly, accepted QUDs and directivesare taken for granted and constrain the legitimate moves in a discourse.The same, we suggest, applies to shared reactive attitudes.

Davidson (1979) and Lewis (1970) propose dealing with non-declaratives by taking them to be synonymous with explicit performatives. They propose that we should take the latter to have, from a semantic standpoint, their compositional truth-conditions. 'Take bus 44!' would just mean the proposition that the speaker thereby requests the audience to take bus 44. On this proposal, we could stick to the original Stalnakerian view of context as a set of propositions. This is what we call the flattening scheme, or simply flattening. We have argued that these views are unmotivated (García-Carpintero 2004, 2015). An assertion that a command is given or a question posed can occur without the command being given or the question posed. Conversely, the non-cognitive attitude/act (the command or the question) can occur without the cognitive one (the belief/assertion that the command or the derogation was made), for instance because the thinker/speaker lacks the conceptual resources to describe the non-cognitive state/act (Starr 2014, 174).

\subsection{Linguistic Presuppositions and Conventional Implicatures}

Conventional implicatures and linguistic presuppositions are conventionally associated with lexical items or constructions. Full competent understanding of lexical items or constructions requires grasping the associated conventional implicatures or presuppositions (GarcíaCarpintero 2018). Now, previous characterizations of expressive presuppositions in either of

\footnotetext{
${ }^{12}$ Salmela and Nagatsu (2016) outline an account of collective emotions that links the intentional structure of joint actions and the underlying cognitive and affective mechanisms. They can function as both motivating and justifying reasons for jointly intentional actions.
} 
these two categories assume a flattened view about their character; and this assumption invites serious criticisms of such accounts. For instance, Schlenker (2007, 238; 2016) offers this characterization for the slur 'honky': The agent of the context believes in the world of the context that white people are despicable. This is a clear-cut condition on a Stalnakerian context. But, as Williamson $(2009,151-2)$ and Nunberg $(2018,284)$ point out, it isn't right as an account of the expressive dimension of slurs, since it does not capture their normative force. The non-bigoted audience of a speaker who utters (1) will refuse to accept the utterance, and may challenge the speaker.

(1) That honky is watching Eurovision tonight.

If the at-issue-content is that the demonstrated white person is watching Eurovision, and the not-at-issue content is that the speaker believes that white people are despicable, the audience can accept both. The audience can thus accept the utterance, since it is true. How come then that we feel we need to object when our interlocutors utter slurs we find objectionable ${ }^{13}$ Moreover, the use of a pejorative is objectionable even when it is clear that the speaker does not think that the target group is bad, i.e., even when the presupposition as analyzed by Schlenker is false, as Schlenker (2016, 725-6) acknowledges. Camp (2013, 333) points out that Potts's conventional implicature account has the same problem, for he characterizes it as just a feature of the subjective emotional state of the speaker - something to the effect that $\mathrm{s} /$ he actually is in a heightened emotional state (Potts 2007, 171; 2012, 2532). The same issue afflicts Saka's (2007, 140-143) sui generis expressivist account, because the expressive part is presented as "S disdains Germans as a class" (ibid., 140).

On Macià's (2014) account, the expressive presupposition of 'charnego' is this: that speakers in the context are willing to treat migrants to Catalonia from other Spanish regions and their descendants with contempt, on account of speaking Spanish, ... Cepollaro $(2015,43)$ considers ascribing to slurs "objective" presuppositions about the target group, instead of the attitudes of the speaker: the target group is despicable for being... Along related lines, Cepollaro \&Stojanovic (2016) would proffer being worthy of contempt because of being a

\footnotetext{
${ }^{13}$ Nunberg $(2018,284)$ points this out: "Why should I care about the attitudes of some pseudonymous bozo who rails about the kikes in a Twitter post - why should it matter to me or to anyone what he thinks or feels about Jews?" But he fails to appreciate that his own account fails for related reasons: "slurs function by evoking the attitudes about the target that are associated with the group who have constituted the word's historical provenance" (ibid., 285). Why should we care about the attitudes of a flock of "pseudonymous bozos"?
} 
migrant to Catalonia from other Spanish regions, ... These are better than Schlenker's and Potts's subjectivist proposals, but we still find them objectionable. An utterance of "Spaniards are not contemptible at all, they are resilient and resourceful; in fact, I just invited a few charnegos to my birthday party" sounds jarring, if not straightforwardly insincere, because it still appears to presuppose a stance of contempt towards Spaniards. Moreover, we find it inadequate to identify what is wrong with using slurs merely with aiming to sneak a falsehood by means of a presupposed, not-at-issue content. We'll come back to this below.

Jeshion (2018) defends an expressive account in which the expressive component is use-conditional as opposed to truth-conditional, along the lines of Kaplan's (1999) and Gutzmann's (2015). But unlike them, she takes the expressive component to be semantic, as in conventional implicature and presuppositional accounts. Like us, she also rejects flattening (op. cit., 82). She offers a compelling analysis of contempt as a moral emotion (based on Mason 2003), which, she contends, allows replies to objections like the ones just made (ibid., $\S \S 5-6)$. We are not sure that it does. As she agrees, "absence of all negative attitudes is incompatible with my account" (ibid., 97). You cannot express contempt, in her sense, if you don't have it. But she grants that there are cases in which speakers fully competent with pejoratives can use them without having the relevant attitude (ibid., 97). She claims that her account can deal with these cases: "speakers fail to express their own contempt, yet hearers rightly regard them as having done so. These cases, in fact, help bolster the theory, for the explanation of speakers exploiting the linguistic convention to express contempt presupposes its very existence" (ibid., 98). A proper elaboration of the explanation that Jeshion envisages requires, we submit, a normative account of the pejorative meaning as the one we propose.

How, then, should contexts and expressive meanings be understood? To recall, the motivation for a presuppositional or conventional implicature account is that pejoratives and slurs seem to project when they occur embedded under negation, in conditionals, in modal constructions, or in propositional attitude ascriptions. But uses of slurs have additional features, which flattened presuppositions cannot explain. Flattened presuppositions can update the common ground even when interlocutors remain unwilling to use the derogatory word, which means that they don't capture what is wrong with the use of the word. Even if they are false (the speaker does not have the putative attitudinal state) the use of a slur by the speaker may be offensive, and the hearer may well object. Tellingly, expressive contents are hard to paraphrase. Finally, as Jeshion (2016) notes, the creation of a new slur seems to contribute to create new forms of harmful exclusion against their targets. We move now to show how our presuppositional account explains these features. 


\subsection{Evaluative and Reactive Attitudes and their Expression}

Some philosophers have argued that emotions are just a particular kind of judgment, to the effect that an object or situation instantiates their "formal objects". Such formal objects are evaluative properties, like, say, that an object or situation is fearsome or disgusting. In the case we have been discussing, it would be that Spanish people are worthy of contempt (cf.Teroni (2007), de Sousa (2014), Todd (2014)). Formal objects are normative properties, ${ }^{14}$ which can perhaps be understood in naturalistic terms. They could be "response-dependent" properties, or relational properties linking organisms and their environments like the "relational themes" that some psychologists of emotions posit (Prinz 2004, 15-6). In both cases, the relevant response should be understood in normative terms: situations that would make the feeling of fear and the readiness for flight fitting, or fitting to banish a group or subject in the case of contempt (Roseman 2018). Being evaluative properties, they can be misapplied to the relevant object or situation.

Like the flattening suggestion for directives and questions, this view would make the application of the standard Stalnakerian model of contexts and presuppositions to the expression of emotions straightforward. But it is nowadays rejected by most researchers (D'Arms and Jacobson 2000, 67; Deonna \& Teroni 2012, ch. 5), for reasons related to those offered in the previous section. On a related view, emotions are not judgments but perceptionlike, "non-conceptual" states, otherwise with similar evaluative contents - cf. Prinz (2004) for a naturalistic version, Tappolet (2016) for a non-reductive one. These views are more plausible, but the difference with the judgment view doesn't matter much when it comes to reactive emotions like those that concern us here. We find them equally problematic, for reasons presented in the previous section (cf. Deonna \& Teroni 2012, ch. 5).

To present our own non-flattening view, we must say how we think of contents. Some theorists make much of the fact that emotive attitudes like fear or contempt can be reported by using nouns as direct objects, rather than that-clauses (Deonna \& Teroni 2015, 299). Some even contend that attitudes reported in that way don't have correctness conditions (Grzankowski 2018, 136). This is wrong. We evaluate attitudes ascribed with nouns in the same way: we say that Alex's fear of that reptile is ungrounded or irrational. Thus, there are the same reasons to ascribe fitting conditions to emotional states reported in the either way

\footnotetext{
${ }^{14}$ Here, we don't distinguish the deontological from the axiological.
} 
(D'Arms and Jacobson 2000; Prinz 2004; Deonna \& Teroni 2012). The difference in the ascription is semantic (Forbes 2018), not ontological. The ascribed attitudes have propositional content, on a deflationary view of them.

On an influential account - still the default in semantics - propositions are sets of worlds, and are understood by Stalnaker (1976) as given by ways or properties the world might have. We endorse Stalnaker's view that propositions are just such properties (Richard 2013). They might be finer-grained than the sets of worlds at which they are instantiated, and thus not identical to them. They can be properties of entities smaller than worlds, as in “truthmaker semantics" Fine (2017). ${ }^{15}$

We are now in a position to present the non-flattening proposal. Emotions themselves are sui generis normative states (Mulligan 1998; D’Arms and Jacobson 2000; Deonna \& Teroni 2012, ch. 7, 2015). The "formal objects" of emotions - say, being worthy of contempt - is not part of represented content, but is the normative condition that appraises the emotional attitude given its content. Speech acts that express emotions are in turn defined by related constitutive norms. In order to accommodate a presuppositional view of pejoratives, we should hence add further illocutionary structure to contexts. The intentional objects of emotional states are the contents of this additional structure. For instance, in the case of 'charnego', Spanish migrants to Catalonia and their descendants are featured as instantiating the condition of generically having such-and-such traits. This condition is taken to make contempt or derogation the fitting emotional reactive attitudes. On plausible assumptions about the conative implications of emotions (Deonna \& Teroni 2015, 302; Tappolet 2016, ch. 2), such people hence become regarded as adequate recipients of mistreatment.

Negative reactive attitudes like resentment or contempt guide our behaviour towards other people (Roseman 2018). They are ways of putting down, punishing, or presenting another person as deserving of the treatment (Jeshion 2018, 91-4, Mason 2003, Roseman 2018). As Manne (2016: p. 197) puts it, they are "morally laden and broadly juridical or legalistic reactions to other presumptively reasonable people". Pejoratives and slurs are expressive of emotions that present their targets as worthy of derogation, a form of putting the target group of persons down and exclude them. As bullies know, derogating does this effectively, and it places the bully above his victim. Reactive attitudes, and the actions they

\footnotetext{
15 Grzankowski $(2018$, 145) grants that on a property view of content, no ontological differences between attitudes objectually and propositionally ascribed remains.
} 
motivate, thus contribute to structure social interactions and create or maintain social hierarchies (Popa-Wyatt \& Wyatt 2018, Jeshion 2018). ${ }^{16}$

We thus characterize the derogatory presuppositional component in normative terms, and define derogation by a constitutive norm. ${ }^{17}$ The norm can be spelled out thus:

DEROGATION: one must derogate group $G$ on account of their having features $F_{1} \ldots$ $F_{n}$ only if group $G$ has $F_{1} \ldots F_{n}$, and contempt fits a group with such features.

When derogation occurs, the generic property-like content that group $\mathrm{G}$ has features $\mathrm{F}_{1}$ $\ldots \mathrm{F}_{\mathrm{n}}$ should be in the context set of propositions whose truth is taken for granted. It should also be in the illocutionarily distinct part of the context (like QUD, To-Do-Lists, etc.) including the contents that make contempt fitting. This evaluation is thus taken for granted and shared by participants in the conversation - in the way the propositional part is commonly taken to be true, the To-Do-List worth pursuing, or the QUD worth investigating. ${ }^{18}$

On our view, the additional "sentimental" structure of contexts should be assumed not only by presuppositional accounts of pejoratives, but also by conventional implicature views (e.g. Potts $(2007,2012)$ and Vallée (2014)). The point applies also to accounts of the expressive dimension as a conversational implicature like Nunberg's (2018), and to DiazLegaspe et al, Diaz-Legaspe 2019, $\$ 4$ related account in terms of register. Even if the expressive content of pejoratives is background but novel "information", if it is left unchallenged it becomes part of the context set and licenses presuppositions down the line. The fact that we need to dissociate ourselves from such a perspective explains our normative reaction to utterances including slurs (cf. McGowan 2004, 2009, Ayala and Vasilyieva 2016).

\section{Objections: "quarantine"; cancellation; non-derogatory uses}

We will now discuss some objections, starting with Camp's (2018, 38-40). She grants Schlenker's $(2007,244 ; 2016,722-3)$ point that the offensive connotations of slurs don't

\footnotetext{
${ }^{16}$ Against what Popa-Wyatt \& Wyatt (2018) and Diaz-Legaspe et al. (2019) suggest, we take it as a fact that contempt is not always addressed to the socially inferior, or meant to make the target inferior, as the Spanish slur for Catalans, 'polaco' (connoting people who avert a shared language) witnesses. Also, contempt (say, towards willed stupidity, or systemic bullshitting) might well be functionally, prudentially, and even morally justified, see Mason (2003, 2018), Jeshion (2013a), Bach (2018), Roseman (2018).

${ }^{17}$ Sbisà (1999) and Langton (2012) offer related views.

18 This can be formally modeled with Gutzmann's (2015) Kaplanian framework, although Gutzmann himself assumes a flattening picture; cf. García-Carpintero forthcoming.
} 
project: they are "quarantined" or "plugged" (Karttunen 1973) by verbs of saying or propositional attitudes. ${ }^{19}$ Some examples that she provides:

(2) John thinks that the spics will have taken over the whole neighbourhood in another couple years. But of course I think it's great that we're developing such a vibrant Latino community.

(3) My father screamed that he would never allow me to marry that kraut Webster. (Kratzer 1999)

(4) Churchill thought Gandhi was the most degenerate wog in all of India. (Anand 2007)

Nunberg $(2018,269)$ offers other examples, like 'Everybody loves to hate a homo', uttered by gay playwright Harvey Fierstein. Nonetheless, Camp argues, “"quarantining' is more difficult and less common with slurs than with standard presuppositions, in a way that calls for explanation" (ibid, 39). But she affords an explanation when she acknowledges Hom's point that even quoted slurs and similarly-sounding words might be as offending to some audiences as endorsed ones. But Lasersohn (2007) defends presuppositional accounts of similar charges and reminds us of Karttunen's (1973) dictum "all plugs are leaky", and he offers a compelling response to Camp:

Because expressives are so emotionally charged, and because their use can carry a significant social risk, I suspect that speakers are especially cautious about using them in embedded contexts where there is a chance of their content "leaking" - except, of course, if the speaker does agree with the content of the expressive and is willing to make this agreement public... This, I suspect, is the correct explanation for why

\footnotetext{
${ }^{19}$ Schroeder $(2009,2014)$ stresses the distinction between hybrid expressions whose expressive content projects in attitude ascriptions and those that don't, but the evidence is messy (Hay 2011). Slurs tend to project but don't always do, as the examples below show. Quoting Bach (1999), Schroeder shows that the implicature of 'but' might well not project in some ascriptions; however, following Potts (2005), we take non-restrictive wh-clauses as paradigm cases of conventional implicatures, and they typically project: John said that Peter, who will be coming soon, is welcome to the party (cp. Bach 2018, 68-9).
} 
expressive content normally projects, rather than any theoretical distinction between presupposed and expressive content (Lasersohn 2007, 228)

Presuppositions are "filtered" or "bound" in some contexts (McCready 2010, 7). They do not project when their triggers occur in the consequent of a conditional whose antecedent states them, or in the second conjunct of a conjunction whose first conjunct states them: if someone broke the computer, it was John who broke it; someone broke the computer, and it was John who did it. Schroeder (2014) uses this point to dismiss the view that the expressive contents we are considering are presuppositions:

I cannot see how to construct a sentence of the form "if P, then Mark is a cheesehead" that does not implicate the speaker in disdain for people from Wisconsin. (Schroeder 2014, 176)

But as Camp $(2018,39)$ points out, Lasersohn $(2007,227)$ had offered an example with the precisely those features:

(5) I consider John a saint. But if he ever screws me over, I'll crush the bastard like a bug!

'The bastard' here is understood as the would-be bastard, and thus the derogatory presupposition appears to be filtered. However, this differs from clear-cut cases, so this line of response doesn't take us far, as Schlenker (2016, 725-6) admits. ${ }^{20}$

We offer another explanation why filtering doesn't generally work for pejoratives and slurs, grounded on the non-propositional character of the expressive presupposition that our account posits. McCready $(2010,9)$ points out that the filtering test has a crucial shortcoming for our purposes, namely the difficulty of finding an adequate paraphrase:

\footnotetext{
${ }^{20}$ In defence of a presuppositional account close to ours, Cepollaro and Stojanovic (2016) also try to explain why filtering doesn't work with slurs. They argue that the so-called phi-features of pronouns (being female for 'she'), which are presuppositions (Heim 2008), don't filter either. We don't think their evidence is persuasive. On our account, the presuppositional component doesn't project simply because it is not a proposition.
} 
It should be noted... that the significance of the result of the binding test depends on the accuracy of the paraphrase. If the paraphrase given is incorrect, or, even worse, if the expressive portion of pejoratives is such that it does not admit a linguistic paraphrase at all, then the test is invalidated.

Now, the "expressive portion" only "admits a linguistic paraphrase" if the flattening strategy work, but we have argued that it doesn't. Remember that questions and directives might be presupposed. Both (6), with the indicated focus, and the pseudo-cleft (7) presuppose question (8) (Roberts 2012):

(6) We want [apple juice $]_{\mathrm{F}}$

(7) What we want is apple juice

(8) What do you want?

(8) has roughly the same force as "I (hereby) ask you what you want". But we cannot filter the question presupposed in (6) and (7) by resorting to this flattening:

(9) \#? If we are asked what we want, we want [apple juice $]_{\mathrm{F}} /$ what we want is apple juice

Remember that the flattening strategy doesn't work because asserting or judging that an illocutionary act obtains is not the same as performing it. The felicity (in the relevant context) of the consequent of (9) requires the existence of the question licensing its focus presupposition - the mere supposition that it does is not enough. We thus conclude that Schroeder's argument illustrates the misleading consequences of ignoring the nature of contexts. The difficulty of filtering just results from the fact that expressive contents are not forceless propositions, which is what antecedents of conditionals or conjuncts must be. ${ }^{21}$ This

${ }^{21}$ Cepollaro \& Stojanovic $(2016,467)$ make a related point, concluding that "there is a crucial difference between rejecting descriptive and evaluative presuppositions". We are very grateful to Craige Roberts for discussion. She agreed with our judgments about (9), although suggested an alternative explanation appealing to (9) being some sort of "biscuit conditional" that we lack the space to discuss here. 
leaves it open whether they are presented as requirements on the common ground (and hence have a presuppositional character), or as new background commitments (and hence are conventional implicatures), or as Nunberg's (2018) Manner implicatures. In any case, Schlenker (2007) and Macià $(2002,2014)$ provide good reasons for the former. ${ }^{22}$

Some of Hom's (2010, 176-9; 2012, 390-1) criticisms of the presuppositional and conventional implicature view have already been discussed, and others have received adequate replies in the literature. Data about projection and "cancellation" are less clear than he assumes, and it can be accounted for, as just argued (cf. Macià 2014, Schlenker 2016, Cepollaro \& Thommen 2019). Intuitions about the truth-values of utterances are much less clear-cut than he and others take them to be (cf. Jeshion 2013a, 317, Marques 2017, ms, Sennet \& Copp 2015), and can be accounted for by both accounts. Hom mentions "nonorthodox" cases that lack derogatory implications. We'll discuss them below (see also Jeshion 2013b, 326-330). Finally, Hom $(2010$, 177) presents the "more fundamental problem with the presupposition account" by quoting Richard (2008, 21): rather than trying to enter something into the conversational record, "someone who is using these words is insulting and being hostile to their targets". Camp $(2018,40,48)$ also regards "weapon uses" to be her main objection against both the presuppositional and the CI accounts.

In response, we claim that there is no real contrast between making a requirement on the conversational record (or an attempt at smuggling it there)of the sort our account posits, and insulting/being hostile to some target. What is assumed when "the speaker 'hurls' the derogating perspective at the hearer like a rock, in an effort to bully them into submission" (Camp 2018, 40) is that the addressee is presented as fitting the negative affective evaluation, i.e. as fitting the derogatory attitude and thereby deserving of mistreatment, of being put down, or punished. That the speaker says this knowing that the addressee will not accept this content update is precisely what the insult and the hostility amount to. While hurting the audience is the main aim of the speaker, we can rely on our account to explain that this is nonetheless a secondary effect of the essential effect of uttering a derogatory word. ${ }^{23}$

\footnotetext{
${ }^{22}$ The Manner implicatures that Nunberg (2018) offers as analogies (uses of 'ain't' in contrast with 'isn't', or 'scandale' in contrast with 'scandal') are explained by features of standard uses of those expressions. But Nunberg's explanation of the relevant features of slursis made in terms of their semantic properties. Also, as Jeshion and others have pointed out, Nunberg would have difficulties in explaining initial uses. Cf. also Cepollaro \& Thommen $(2019, \S 4)$.

${ }^{23}$ Stalnaker $(1978,87)$ replies to an objection to his account of assertions as proposals to update the common ground based on similar "weapon uses" of them, as in: you are a fool. Note that the "weapon" use may occur in a presupposition (you know that you are a fool) or appositive conventional implicature (you, fool, are ruining my
} 
Strawsonian reactive attitudes structure our social interactions with others. A speaker who insults a hearer puts the hearer down. The speaker who blatantly violates basic cooperative conversation principles also claims a stronger position of dominance over his audience. The speaker who knows that the hearer rejects the presupposed derogatory perspective abuses conversational cooperative principles to assert his power. That is why it is irrelevant to him whether the hearer accommodates the derogatory perspective. Bullying the other into submission is stronger if the speaker bloats his dominance through a blatant disregard for conversational norms (cf. also Langton \& West 1999, 309). Our view thus has the resources to explain why uses of slurs insult.

Our proposal is compatible with the appropriation of slurs and pejoratives. On the expressive presuppositional account, pejoratives and slurs make normative requirements on the common ground. They make the requirement that interlocutors share reactive attitudes directed against some people or group of people, which are taken to be fitting. The successful appropriation of a derogatory term by members of the target audience requires the erosion of such normative requirements. Bicchieri (2017) offers a theory about normative change. She says that deviating from social norms has personal and social costs. For them to decrease, a certain number of other people should also deviate from the norm to effect change. The number of people required will depend on the social practice that puts the normative requirement in force, cf. Bicchieri $(2017,108)$. Merely intending to change a norm is usually insufficient. To alter normative requirements made by a use of a slur, the empirical and normative expectations of a larger number of people must be changed (Bicchieri, 2017: 52$60)$.

Finally, there are cases where the expressive presupposition associated with a slur is not present at all, as we have argued. In cases where a slur is mentioned, as in the context of an academic paper or in juridical contexts where testimony is registered by a court stenographer, the mentioned slurs or pejoratives do not make requirements on the context. In such contexts, used slurs do not make an expressive derogatory act. This also happens in the cases mentioned above where the presuppositions can be successfully plugged, filtered, or otherwise "quarantined".

day). The speaker knows very well that the presupposition is not in the common ground and is not going to be accommodated, and that the conventional implicature will not be accepted. But she relies on what these acts constitutively are to achievethe goal of insulting her audience. 


\section{Conclusion}

In this paper, we assumed a broadly Stalnakerian view of contexts, where they are meanings shared by the speakers participating in a linguistic exchange. But we rejected Stalnaker's "info-centric" view. Contexts are not just propositions, they are representational contents together with commitments towards them in different modes by speakers. We rejected also the "flattening" strategy that reduces non-declaratives to declaratives, and we argued that flattening will not work in the case of pejoratives and slurs either.

The normative presuppositional account has several virtues. It explains the fact that the affective dimension associated with a use of a pejorative normally projects. It explains why a slur insults even when an audience resists accommodating the presupposition associated with it. The view is consistent with the fact that it is difficult to articulate the communicated derogatory content. Finally, the account is compatible with more general theories about changes of social norms, helping to predict the conditions in which reclamation and appropriation is successful, and explaining why mentioning slurs or pejoratives in certain contexts is not derogatory. ${ }^{24}$

\section{Acknowledgements}

Financial support was provided by the DGI, Spanish Government, projects FFI2016-80588-R and FFI2015-73767-JIN; award ICREA Academia 2018, Generalitat de Catalunya; and European Union's Horizon 2020 programme under Grant Agreement no. 675415, Diaphora. Versions of this material were presented at the ESPP 2016, St. Andrews, Context-17, Paris, and SIUCC27, Vitoria; we are thankful to audiences for their comments. We are indebted to comments by Liz Camp, Bianca Cepollaro, Nate Charlow, Robin Jeshion, Josep Macià, Craige Roberts, Philippe Schlenker, Isidora Stojanovic, Dan Zeman, and two anonymous referees for this volume. Thanks to Michael Maudsley for his grammatical revision.

\section{References}

Anand, Pranav 2007. “Re-expressing Judgment.” Theoretical Linguistics 33(2), 199-208.

\footnotetext{
${ }^{24}$ We have thus showed how our account explains (better than alternatives, we submit) four of the five desiderata listed by Bolinger $(2017,439)$. We haven't properly discussed the one remaining, Offensive Variation, that "not all slurs, even if co-referential, appear to be equally offensive". This depends on the socialnorms-related issues we have touched upon at some places, on which we cannot properly elaborate here.
} 
Bach, Kent 1999. “The Myth of Conventional Implicatures.” Linguistics and Philosophy 229, 327-66.

Bach, Kent 2018. "Loaded Words. On the Semantics and Pragmatics of Slurs." In: Bad Words: Philosophical Perspectives on Slurs, edited by D. Sosa, Oxford: OUP, 60-76.

Bicchieri, Cristina 2017.Norms in the Wild- Oxford: OUP.

Bolinger, Renée J. 2017. “The Pragmatics of Slurs.” Noûs 51(3), 439-462.

Camp, Elizabeth 2013. "Slurring Perspectives.” Analytic Philosophy 54(3), 330-49.

Camp, Elizabeth 2018. “A Dual Act Analysis of Slurs.”In: Bad Words: Philosophical Perspectives on Slurs, edited by D. Sosa, Oxford: OUP, 29-59.

Carlson, Lauri 1982. Dialogue Games: an Approach to Discourse Analysis. Dordrecht, The Netherlands: D. Reidel.

Cepollaro, Bianca 2015. "In defense of a presuppositional account of slurs." Language Science 52, 36-45.

Cepollaro, B., and Stojanovic, I. 2016. "Hybrid Evaluatives: In Defense of a Presuppositional Account." Grazer Philosophische Studien 93, 458-488.

Cepollaro, B., and Thommen, T. 2019. "What's wrong with truth-conditional accounts of slurs.” Linguistics and Philosophy DOI: 0.1007/s10988-018-9249-8.

Charlow, Nate 2018. "Clause-Type, Force, and Normative Judgment in the Semantics of Imperatives." In: New Work in Speech Acts, edited by D. Fogal, D. Harris and M. Moss Oxford: OUP, 67-98.

Davidson, Donald 1979. "Moods and Performances." In: Meaning and Use, edited by A. Margalit, Dordrecht: D. Reidel, 9-20.

D'Arms, J. \& Jacobson, D. 2000. “The Moralistic Fallacy: On the 'Appropriateness' of Emotions." Philosophy and Phenomenological Research 61(1), 65-90.

Deonna, J., \& Teroni, F. 2012. The Emotions. London: Routledge.

Deonna, J., \& Teroni, F. 2015. “Emotions as Attitudes.” Dialectica 69, 293-311.

de Sousa, Ronald 2014. "Emotion.” In: The Stanford Encyclopedia of Philosophy (Spring 2014 Edition), edited by Edward N. Zalta, URL = http://plato.stanford.edu/archives/spr2014/entries/emotion/

Diaz-Legaspe, Justina 2019. "What is a slur?” Philosophical Studies DOI: 10.1007/s11098019-01259-3.

Diaz-Legaspe, J., Liu, Ch., \& Stainton, R. 2019. "Slurs and register: A case study in meaning pluralism." Mind and Language DOI: 10.1111/mila.12236. 
Diaz-Leon, Esa 2019. "Pejorative Terms and the Semantic Strategy." Acta Analytica Online First, DOI 10.1007/s12136-019-00392-2.

Fine, Kit 2017. "Truthmaker Semantics.” In: A Companion to the Philosophy of Language, edited by B. Hale, C. Wright and A. Miller, $2^{\text {nd }}$ ed., Oxford: Blackwell, 556-577.

Forbes, Graeme 2018. "Content and Theme in Attitude Ascriptions.” In: Non-Propositional Intentionality, edited by A. Grzankowski \& M. Montague, Oxford: OUP, 114-133.

García-Carpintero, Manuel 2004. "Assertion and the Semantics of Force-Markers." In: The Semantics/Pragmatics Distinction, edited by C. Bianchi, CSLI Lecture Notes, Chicago: The University of Chicago Press, 133-166.

García-Carpintero, Manuel 2015. "Contexts as Shared Commitments." Frontiers in Psychology, 6:1932, DOI: 10.3389/fpsyg.2015.01932.

García-Carpintero, Manuel 2018. "On the Nature of Presupposition: A Normative Speech Act Account.” Erkenntnis, online first, DOI: 10.1007/s10670-018-0027-3.

García-Carpintero, Manuel forthcoming. "Metasemantics: A Normative Perspective (and the Case of Mood)." In: The Cambridge Handbook of the Philosophy of Language, edited by P. Stalmaszczyk, Cambridge: CUP.

Gibbard, Alan 1990, Wise Choices, Apt Feelings. Oxford: OUP.

Green, Mitchell 2017. “Conversation and common ground.” Philosophical Studies 174, 1587 1604.

Grzankowski, Alex 2018. "A Relational Theory of Non-Propositional Attitudes.” In NonPropositional Intentionality, edited by A. Grzankowski \& M. Montague, Oxford: OUP, 134-151.

Gutzmann, Daniel (2015): Use-Conditional Meaning, Oxford: OUP.

Hay, Ryan J. 2011. "Hybrid Expressivism and the Analogy between Pejoratives and Moral Language." European Journal of Philosophy 21(3), 450-474.

Heim, Irene 2008. "Features on Bound Pronouns." In Phi Theory, D., Harbour, D. Adger, \& S. Béjar (eds.), Oxford: OUP.

Hom, Christopher 2008. “The Semantics of Racial Epithets.” Journal of Philosophy 105, 41640.

Hom, Christopher 2010. “Pejoratives.” Philosophy Compass 5(2), 164-185.

Hom, Christopher 2012. “The Puzzle of Pejoratives.” Philosophical Studies 159, 383-405.

Hom, C., \& May, R. 2013. "Moral and semantic innocence.” Analytic Philosophy 54(3), 293313.

Jeshion, Robin 2013a. "Slurs and Stereotypes.” Analytic Philosophy 54, 314-329. 
Jeshion, Robin 2013b. "Expressivism and the Offensiveness of Slurs." Philosophical Perspectives 54, 307-335.

Jeshion, Robin 2016. "Slur creation, bigotry formation: the power of expressivism." Phenomenology and Mind (11), 130-139.

Jeshion, Robin 2018. "Slurs, Dehumanization, and the Expression of Contempt." In: Bad Words: Philosophical Perspectives on Slurs, edited by D. Sosa, Oxford: OUP, 77-107.

Kaplan, David 1989. “Demonstratives.” In: Themes from Kaplan, edited by J. Almog, J. Perry and H. Wettstein, Oxford: Oxford University Press, 481-563.

Kaplan, David 1999. “The Meaning of 'Ouch' and 'Oops'.” UCLA, ms.

Karttunen, Lauri 1973. "Presuppositions and Compound Sentences.” Linguistic Inquiry 4(2): 169-193.

Kratzer, Angelika 1999. "Beyond Ouch and Oops: How Descriptive and Expressive Meaning Interact." In: Cornell Conference on Theories of Context Dependency, Ithaca, NY: Cornell University.

Langton, Rae 2012. "Beyond Belief." In: Speech and Harm, edited by K. McGowan \& I. Maitra, Oxford: OUP, 126-147.

Langton, R. \& West, C. 1999. “Scorekeeping in a Pornographic Game.” Australasian Journal of Philosophy 77, 3, 303-319.

Lasersohn, Peter 2007. "Expressives, perspective, and presupposition." Theoretical Linguistics, 33: 223-230.

Lewis, David 1970. “General Semantics.” Synthèse 22, 18-67.

Lewis, David 1979. "Scorekeeping in a Language Game.” Journal of Philosophical Logic (8): $339-59$.

Lewis, David 1980. "Index, Context, and Content.” In: Philosophy and Grammar, edited by S. Kanger \& S. Öhman, Dordrecht: Reidel.

Lycan, William 2015. "Slurs and lexical presumption.” Language Sciences, 52, 3-11.

Macià, Josep 2002. "Presuposición y significado expresivo.” Theoria: 3 (45): 499-513.

Macià, Josep 2014. "Expressive Meaning and Presupposition." Handout for a talk at the Names, Demonstratives, and Expressives conference in Gargnano, Italy.

Marques, Teresa 2017. "Pejorative discourse is not fictional." Thought: A Journal of Philosophy, 6(4): 250-260. DOI: 10.1002/tht3.258. 2017. iLئi:

Marques, Teresa 2019. “'Beasts in Human Form': how dangerous speech harms.” Araucaria: Revista Iberoamericana de Filosofía, Política, Humanidades, y Relaciones 
Internacionales, special issue edited by B. Brecher \& V. Ordóñez, Narratives of Power: Demagogues, Politics and Morality at the Start of the 21 st Century.

Marques, Teresa (ms). "Pejoratives \& Oughts".

Marques, Teresa \& García-Carpintero, Manuel 2014. "Disagreement about taste: commonality presuppositions and coordination." Australasian Journal of Philosophy, 72 (4), 701-23, DOI: 10.1080/00048402.2014.922592.

Mason, Michele 2003. “Contempt as a Moral Attitude.” Ethics 113, 234-272.

Mason, Michele 2018. "Contempt: At the Limits of Reactivity." In The Moral Psychology of Contempt, edited by M. Mason, Lanham, MD: Rowman and Littlefield, 173-192.

McCready, E. 2010. "Varieties of conventional implicature." Semantics \& Pragmatics 3(8), $1-57$.

Mulligan, Kevin 1998. "From Appropriate Emotions to Values.” Monist, 81(1): 161-88.

Nunberg, Geoffrey 2018. "Speech Acts in Discourse Contexts.”In: New Work in Speech Acts, edited by D. Fogal, D. Harris and M. Moss Oxford: OUP, 237-295.

Popa-Wyatt, M., \& Wyatt, J. 2018. "Slurs, roles and power." Philosophical Studies 175, 2879-2906.

Portner, Paul 2016. "Imperatives.” In: Cambridge Handbook of Semantics, edited by Maria Aloni and Paul Dekker, Cambridge: CUP, 593-627.

Potts, Christopher 2005. The Logic of Conventional Implicatures, Oxford: OUP.

Potts, Christopher 2007. “The Expressive Dimension.” Theoretical Linguistics 33(2), 165198.

Potts, Christopher 2012. "Conventional Implicature and Expressive Content." In: Semantics: An International Handbook of Natural Language Meaning, edited by C. Maienborn, K. von Heusinger, \& P. Portner, Mouton de Gruyter, Berlin, 3, 2516-2535.

Prinz, Jesse 2004. Gut Reactions. Oxford: Oxford University Press.

Richard, Mark 2008. When Truth Gives Out. Oxford: Oxford University Press.

Richard, Mark 2013. "What are Propositions?" Canadian Journal of Philosophy, 43(5-6), 702-719.

Roberts, Craige 2012. "Information Structure in Discourse: Towards an Integrated Formal Theory of Pragmatics", Semantics \& Pragmatics, 49, 5, 1-69.

Roberts, Craige 2018. "Speech Acts in Discourse Contexts." In: New Work in Speech Acts, edited by D. Fogal, D. Harris and M. Moss Oxford: OUP, 317-359. 
Roseman, Ira J. 2018. “Rejecting the Unworthy: The Moral Psychology of Contempt.'In: The Moral Psychology of Contempt, edited by M. Mason, Lanham, MD: Rowman and Littlefield, 107-130.

Saka, Paul 2007. How to Think about Meaning. Dordrecht: Springer.

Sbisà, Marina 1999. "Ideology and the Persuasive Use of Presupposition.” In: Language and Ideology I, edited by J. Verschueren, Antwerp: International Pragmatics Association, 492-509.

Schlenker, Philippe 2007. "The Expressive Dimensions.” Theoretical Linguistics 33(2), 237245.

Schlenker, Philippe 2016.“The Semantics-Pragmatics Interface.” In: Cambridge Handbook of Semantics, edited by Maria Aloni and Paul Dekker, Cambridge: CUP, 664-727.

Schroeder, Mark 2009. “Hybrid Expressivism: Virtues and Vices.” Ethics 119, 257-309.

Schroeder, Mark 2014. "The Truth in Hybrid Semantics." In: Having it Both Ways: Hybrid Theories and Modern Metaethics, edited by G. Fletcher \& M. Ridge, Oxford: OUP, 273-293.

Sennet, A., \& Copp, D. 2015. "What kind of a mistake is it to use a slur?" Philosophical Studies 172:1079-1104, DOI: 10.1007/s11098-014-0338-4.

Stalnaker, Robert 1978. “Assertion.” In: P Cole (ed.) Syntax and Semantics 9, New York: Academic Press, 315-332. In: Robert Stalnaker, Context and Content, Oxford UP, Oxford, 1999, 78-95, to which we refer.

Stalnaker, Robert 2014. Context, Oxford: OUP.

Starr, William 2014. "Mood, Force and Truth.” Protosociology 31, 160-181.

Tappolet, Christine 2016. Emotions, Values, and Agency. Oxford: Oxford University Press. Teroni, Fabrice 2007. "Emotions and Formal Objects.” Dialectica 61 (3), 395-415.

Thomason, Richmond H. 1990. “Accomodation, Meaning, and Implicature: Interdisciplinary Foundations for Pragmatics.” In: Intentions in Communication, edited by P.R. Cohen, J. Morgan, and M.E. Pollack, Cambridge, MA: MIT Press, pp. 325-63.

Todd, Cain 2014. "Emotion and Value." Philosophy Compass 9/10, 702-712.

Vallée, Richard 2014. "Slurring and common knowledge of ordinary language."Journal of Pragmatics 61, 78-90.

Williamson, Timothy 2009. "Reference, Inference, and the Semantics of Pejoratives." In: The Philosophy of David Kaplan, edited by J. Almog and P. Leonardi, Oxford, OUP, 137158. 